\title{
Recent Advances in CNS P2X7 Physiology and Pharmacology: Focus on Neuropsychiatric Disorders
}

\author{
Anindya Bhattacharya* \\ Neuroscience Therapeutic Area, Janssen Research and Development, LLC, San Diego, CA, United States
}

The ATP-gated P2X7 ion channel is an abundant microglial protein in the CNS that plays an important pathological role in executing ATP-driven danger signal transduction. Emerging data has generated scientific interest and excitement around targeting the P2X7 ion channel as a potential drug target for CNS disorders. Over the past years, a wealth of data has been published on CNS P2X7 biology, in particular the role of P2X7 in microglial cells, and in vivo effects of brain-penetrant P2X7 antagonists. Likewise, significant progress has been made around the medicinal chemistry of CNS P2X7 ligands, as antagonists for in vivo target validation in models of CNS diseases, to identification of two clinical compounds (JNJ-54175446 and JNJ-55308942) and

OPEN ACCESS

Edited by:

Kenneth A. Jacobson,

National Institutes of Health $(\mathrm{NIH})$,

United States

Reviewed by:

Hendra Gunosewoyo,

Curtin University, Australia

Carlos De Torre,

IMIB-Arrixaca, Spain

*Correspondence:

Anindya Bhattacharya

abhatta2@its.jnj.com

Specialty section:

This article was submitted to

Experimental Pharmacology and Drug

Discovery,

a section of the journal

Frontiers in Pharmacology

Received: 13 October 2017

Accepted: 10 January 2018

Published: 01 February 2018

Citation:

Bhattacharya A (2018) Recent Advances in CNS P2X7 Physiology and Pharmacology: Focus on

Neuropsychiatric Disorders.

Front. Pharmacol. 9:30.

doi: 10.3389/fphar.2018.00030 finally, discovery of P2X7 PET ligands. This review is an attempt to bring together the current understanding of P2X7 in the CNS with a focus on P2X7 as a drug target in neuropsychiatric disorders.

Keywords: P2X7, microglia, depression, IL-1beta, schizophrenia, bipolar disorder, neuroinflammation, neuropsychiatry

\section{INTRODUCTION}

P2X7 is an ATP-gated ion channel; activation of the ion channel by ATP leads to opening of the pore causing non-selective flux of $\mathrm{Ca}^{2+}, \mathrm{Na}^{+}$, and $\mathrm{K}^{+}$ions (Bartlett et al., 2014). In addition to the non-selective cation conductance, P2X7 channel opening under constant stimulation to ATP is believed to form a "macro-pore," the function of which has remained elusive; pharmacologically, there is no antagonist or modulator of P2X7 that selectively disrupts the macro-pore and as such the physiological relevance of the macro-pore has been debated and recently challenged (Pippel et al., 2017). In addition to ion flux, the best studied downstream function of P2X7 is the release of pro-inflammatory cytokines, IL-1 $\beta$ and IL-18 (He et al., 2017) that functions through the recruitment of the NLRP3 inflammasome complex (Giuliani et al., 2017). Since P2X7 is abundantly expressed in blood cells, IL-1 $\beta$ release in the blood has been used as a biomarker of P2X7 activity and has been used in both preclinical and clinical assessment of target engagement (Stock et al., 2012; Letavic et al., 2017). Although the P2X7-dependent NLRP3mediated IL- $1 \beta$ release is the best characterized signature of P2X7 activity in vivo, there are numerous other physiological endpoints (pyroptosis, membrane blebbing shedding of cell surface proteins, microvesicle/exosome release to even modulation of synaptic events), some or all of which may contribute to P2X7-driven pathology (Bartlett et al., 2014). P2X7 function is even modulated by cholesterol and other membrane lipids (Karasawa et al., 2017). Within the CNS P2X7 is abundantly expressed in microglial cells (Bhattacharya and Biber, 2016) and P2X7 activation causes IL-1 $\beta$ (and IL-18) release, neuroinflammation, and microglial activation (Monif et al., 2010; 
Bhattacharya et al., 2013; He et al., 2017). In addition to microglia, astrocytes and oligodendrocytes also express this ion channel subtype in the CNS; the expression of P2X7 in CNS neurons is inconsistent and sometimes controversial (Illes et al., 2017). Even though P2X7 expression is abundant in microglia (and in peripheral immune cells), the channel is "silent" under normal physiology where ATP concentrations do not reach high micromolar levels to activate the ion channel (Bhattacharya and Biber, 2016). As such, from a drug discovery perspective, P2X7 is an ideal drug target as antagonism of a silent channel by true neutral antagonists would not cause any serious target mediated (adverse) effects, i.e., antagonism will only elicit when the channel is activated by high ATP concentrations (i.e., ondemand activation, danger signal), which is believed to be achieved during pathology of neuroinflammatory disorders of the CNS such as stroke, epilepsy, multiple sclerosis, chronic neurodegenerative, and neuropsychiatric diseases. There have been several excellent and comprehensive review articles on P2X7 highlighting the biology, genetics, and disease relevance (Bartlett et al., 2014; Sperlagh and Illes, 2014; De Marchi et al., 2016; Park and Kim, 2017); for this mini-review, the focus is entirely on the role of CNS P2X7 in neuropsychiatry, with an emphasis on pharmacology and medicinal chemistry of brain-penetrant P2X7 antagonists including the identification of the two CNS P2X7 clinical compounds, JNJ-54175446 and JNJ-55308942 (see later).

\section{ROLE OF P2X7 IN NEUROPSYCHIATRIC DISORDERS}

Chronic inflammation is one of the core underpinnings of many diseases; relatively recent scientific literature over the past few years points to the role of peripheral and central inflammation in neuropsychiatric diseases (Leighton et al., 2017; Wetsman, 2017). With the relatively recent discovery of CNS lymphatics in the meningeal tissue that drains CSF into deep cervical nodes (Louveau et al., 2015), and emerging science supporting the possibility of compromised blood-brain, bloodCSF, blood-choroid plexus barriers in chronic diseases of the CNS, the role of immune cells and their signaling partners in CNS pathophysiology are beginning to be thoroughly appreciated (Wohleb et al., 2016). As has happened in the space of immunooncology, there is a now a growing body of scientific literature that supports a role of immunology in neuropsychiatry, the emerging discipline of neuroimmunopsychiatry (Bhattacharya et al., 2016). Perhaps, it is not a mere coincidence that several inflammatory disorders are co-morbid with depression, bipolar disorder, and schizophrenia (Miller et al., 2017). This has been supported by immune-related gene enrichment in patients (Jansen et al., 2016; Leday et al., 2018).

Within the CNS, microglia are considered as innate immune cells and one of consequences of activated microglia results in neuroinflammation as defined by the release of several pro-inflammatory cytokines including IL-1 $\beta$. This cytokine is present at higher levels in plasma, CSF, and postmortem brain tissue of individuals with mood disorders (Söderlund et al., 2011; Jones and Thomsen, 2013). This cytokine has been linked with geriatric depression and postpartum depression as well (Corwin et al., 2008; Diniz et al., 2010). In animal models of stress-induced depression, it was shown that IL$1 \beta$ signaling was critical to the development of depression-like phenotype (Koo and Duman, 2009). Due to this body of data it is reasonable to hypothesize that targeting P2X7, upstream of NLRP3 and IL-1 $\beta$ signaling, with CNS penetrable P2X7 antagonists would be beneficial for treating mood disorders. As such, there is a growing body of literature that strengthens the role of P2X7-IL-1 $\beta$ pathway in mood disorders including depression and bipolar disorder (Chrovian et al., 2014; Stokes et al., 2015; Bhattacharya and Biber, 2016; Bhattacharya and Drevets, 2017). Some of the key data supporting the role of P2X7 in models of depression, mania, and schizophrenia is discussed below.

P2X7 activation produces microglial activation (Monif et al., 2010). Microglial activation has been clinically demonstrated in depression, bipolar disorder, and schizophrenia by use of PET ligands designed to target TSPO, a mitochondrial protein used as a surrogate of microglial activation (Mondelli et al., 2017). As such, it is plausible that P2X7 plays a role in the etiology of neuropsychiatric diseases, maybe in a subset of patients with neuroinflammation. Recently, P2X7 has come to the light as a potential molecular player in schizophrenia (Kovanyi et al., 2016). This is not surprising given the role of microglia and neuroinflammation in schizophrenia (Laskaris et al., 2016). For depression and bipolar disorder, there is even more growing genetic evidence of $\mathrm{P} 2 \mathrm{X} 7$, although the penetrance and frequency of the SNPs to disease susceptibility and protection is not clearly understood. It is perhaps not surprising that the data is equivocal, clouded with both positive and negative associations (Barden et al., 2006; Lucae et al., 2006; Hejjas et al., 2009; Backlund et al., 2011, 2012; Soronen et al., 2011; Halmai et al., 2013). One of the most reported P2X7 SNP is rs2230912. The rs2230912-G allele is known to exhibit a gainof-function for IL-1 $\beta$ release from human monocytes (Stokes et al., 2010). A recent meta-analysis was reported for rs 2230912 and the authors concluded strong association of rs2230912 with depression and bipolar disorder (Czamara et al., 2017), although negative association meta-analysis also exists for this particular SNP (Feng et al., 2014). In addition to rs2230912, there are additional SNPs on the $p 2 r x 7$ gene (rs1718119, rs3751143, rs1653624) that may shed additional insight into the role of P2X7 SNPs and disease susceptibility; perhaps, more detailed haplotype analysis is needed to understand the relationship between allelic variation, function (IL-1 $\beta$ release), and disease protection and/or susceptibility. In addition to the human genetic literature, emerging science in animal models of despair and anhedonia has been supportive of the P2X7 hypothesis of mood disorders. Several groups have demonstrated an anti-depressant and anti-manic phenotype of P2X7 knockout mice (Basso et al., 2009; Boucher et al., 2011; Csolle et al., 2013a,b; Wilkinson et al., 2014). Whether the knockout phenotypes, in particular the acute despair like behaviors seen in forced swim immobility measurements, can be robustly recapitulated in rodents with pharmacological specificity remains to be seen as it is not clear how ATP would activate central P2X7 channels in an 
acute stressful setting. Where P2X7 probably plays a more significant role is in chronic settings of stress, where IL-1 $\beta$-driven microglial activation and neuroinflammation has been shown to upregulate and P2X7 antagonism may be efficacious. In line with this hypothesis, in a model of sucrose consumption that is reflective of hedonic behavior, pharmacological antagonism of P2X7 restored the deficit observed in drinking sucrosewater (anhedonia) either under chronic stress or by systemic administration of lipopolysaccharides (LPS) (Csolle et al., 2013b). Consistent with these observations, recent data with P2X7 selective, brain-penetrant antagonists demonstrated efficacy in chronic models of stress (Lovenberg et al., 2015; Iwata et al., 2016; Yue et al., 2017); these findings point to a pathway of stress mediated ATP-driven activation of P2X7-NLRP3-IL-1 $\beta$ pathway, leading to microglial activation (pro-inflammatory) and neuroinflammation. A recent study demonstrated enhanced IL-1 $\beta$ release in the brain, upregulation of P2X7 mRNA, and microglial activation in a chronic stress paradigm (Tan et al., 2017). Chronic stress is known to contribute to clinical depression (Calcia et al., 2016) and as such there is hope that P2X7 antagonists with good CNS penetration and drug likeliness will proceed into clinical testing as novel mechanisms for mood disorders. There is also a recent publication indicating the role of $\mathrm{P} 2 \mathrm{X} 7$ channels in modulating stress-mediated spine density downregulation and P2X7 knock out mice are protective from this decrease in spine density (Otrokocsi et al., 2017). In addition to depression, blockade of P2X7 may be useful as mood stabilizer in bipolar disorder (Gubert et al., 2014). P2X7 antagonism was efficacious in amphetamine-induced sensitization of hyperactivity (Bhattacharya et al., 2013; Lord et al., 2014), and similar phenotypes were observed in P2X7 knockout mice (Gubert et al., 2014). Taken together, the body of emerging data suggests a potential therapeutic utility of brain-penetrant P2X7 antagonists in mood disorders, especially targeting treatment resistant patient sub-populations or as an adjunct to current pharmacotherapy for efficacy maintenance.

\section{P2X7 PHARMACOLOGY: BRAIN-PENETRANT ANTAGONISTS}

Significant progress has been made toward identification of brain-penetrant P2X7 antagonists. This spans medicinal chemistry efforts from identification of tool molecules to selection of brain-penetrant clinical candidates JNJ-54175446 (Letavic et al., 2017) and JNJ-55308942 (Chrovian et al., 2017). Unlike the Pfizer and AstraZeneca clinical compounds (Figure 1), the Janssen molecules retain rodent activity providing the discovery team to develop robust target engagement assays to drive the chemistry program; in addition, rodent activity provided the team with an opportunity to test the molecules in rodent models of disease, an important missing link in the prior two clinical compounds (CE-224,535 and AZD-9056). Medicinal chemistry efforts toward identification of brainpenetrant P2X7 ligands in the industry are summarized in Figure 2. The Pfizer molecule (compound 7f) was reported to be drug like with a low clearance, long half-life in rats,

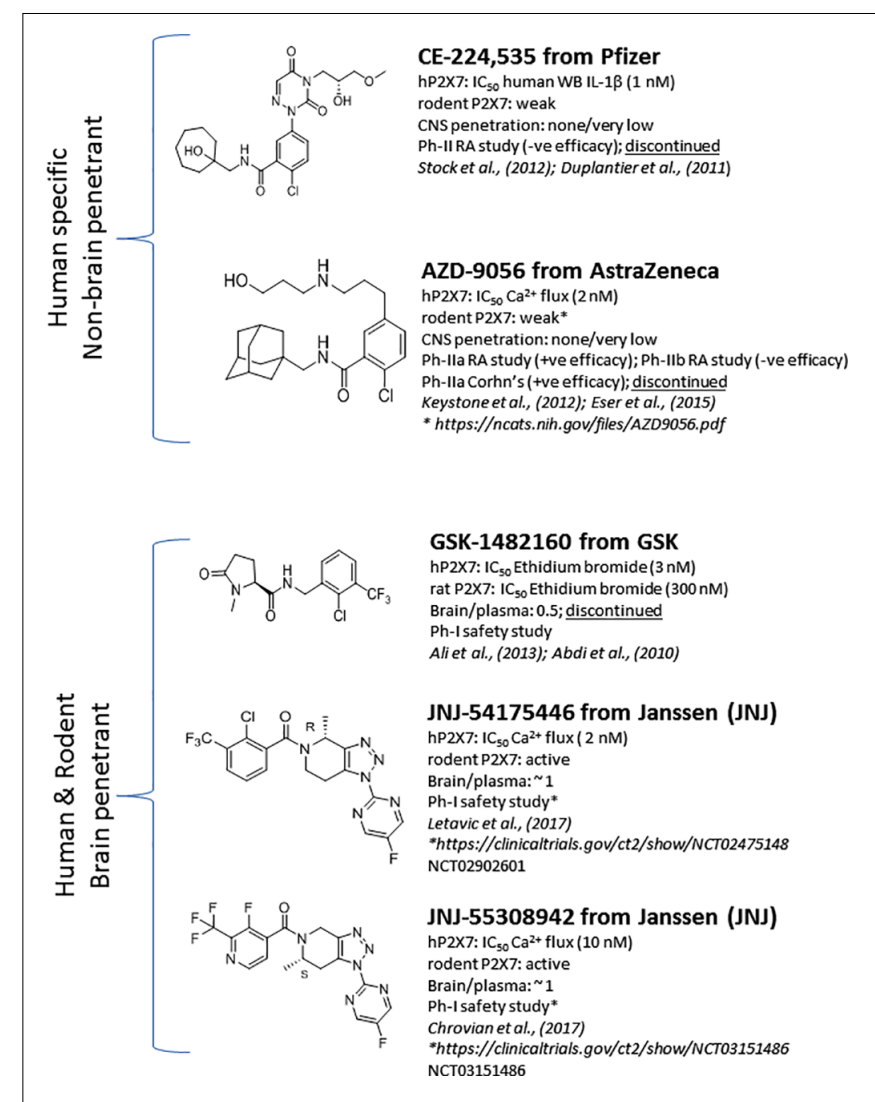

FIGURE 1 | P2X7 antagonists that transitioned into clinical development.

and good CNS exposure (brain/plasma of 1.3) (Chen et al., 2010). Medicinal chemistry groups at Abbott Laboratories (now Abbvie) and GlaxoSmithKline (GSK) were the pioneers in discovering scaffolds with both rodent potency and lowmoderate CNS permeability (Nelson et al., 2006; Beswick et al., 2010; Chen et al., 2010). The group at Janssen has published several papers disclosing P2X7 antagonists with excellent brain penetration (Figure 2) and focusing on brain P2X7-mediated pharmacodynamic endpoints (Bhattacharya et al., 2013; Letavic et al., 2013; Lord et al., 2014; Savall et al., 2015). JNJ-47965567 and JNJ-42253432 demonstrated activity at rodent and human P2X7, had good rat pharmacokinetic profiles, and excellent brain penetration when dosed subcutaneously to allow for $>80 \%$ brain P2X7 occupancy, as judged by ex vivo autoradiography in rat brain slices. Docking studies with JNJ-47965567 reveal an allosteric binding site (Karasawa and Kawate, 2016). More recently, Janssen disclosed several additional classes of P2X7 antagonists, beginning with a series of fused 1,2,3-triazoles. A closer look at the nuances of adding the methyl substituents to the 1,2,4-triazolopyrazine core revealed a strong enantiomeric preference of the P2X7 ion channel. Chiral separation and ultimately enantioselective synthesis demonstrated the (S)-7methyl derivative (human $\mathrm{IC}_{50}$ of $7.7 \pm 2.6 \mathrm{nM}$ and rat $\mathrm{IC}_{50}$ of $8.0 \pm 2.9 \mathrm{nM}$ ) was highly favored over the (R)-8-methyl derivative devoid of any significant P2X7 activity (human $\mathrm{IC}_{50}$ of $1560 \mathrm{nM}$ and rat $\mathrm{IC}_{50}$ of $2240 \mathrm{nM}$ ). JNJ-54140515 was 

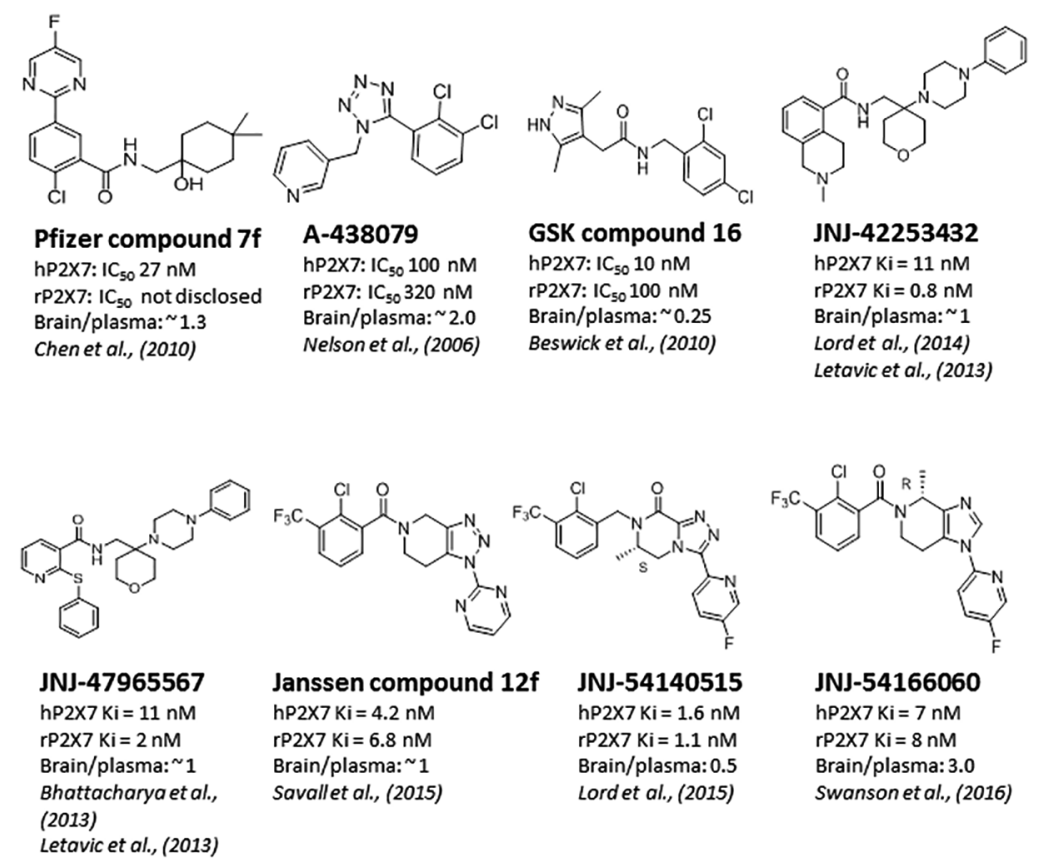

JNJ-54140515 $\mathrm{hP} 2 \times 7 \mathrm{Ki}=1.6 \mathrm{nM}$ $\mathrm{rP} 2 \times 7 \mathrm{Ki}=1.1 \mathrm{nM}$ Brain/plasma: 0.5 Lord et al., (2015)

JNJ-54166060

$\mathrm{hP} 2 \mathrm{X} 7 \mathrm{Ki}=7 \mathrm{nM}$ $\mathrm{rP2} 2 \mathrm{Ki}=8 \mathrm{nM}$ Brain/plasma: 3.0 Swanson et al., (2016)

FIGURE 2 | Brain-penetrant P2X7 antagonists.

discovered from this series and was shown to readily cross the blood-brain barrier facilitating the high level of brain P2X7 occupancy. In addition to good in vivo properties, this ligand was highly selective and was tritiated to produce a radioligand for P2X7 (Lord et al., 2015). JNJ-54166060 was discovered from an imidazopyridine scaffold (Swanson et al., 2016) and was shown to have a significant brain/plasma ratio of close to 3 . Although the brain concentrations were approximately threefold greater than plasma levels, free plasma and free brain concentrations were similar after correcting for brain binding (1.5\% free) and plasma protein binding (5.5\% free). The compound demonstrated an $\mathrm{ED}_{50}$ of $2.3 \mathrm{mg} / \mathrm{kg}$ oral dose.

The discovery of the clinical compound JNJ-54175446 (Figure 1; NCT02902601) and JNJ-55308942 (Figure 1; NCT03151486) is described in detail by Letavic et al. (2017) and Chrovian et al. (2017). JNJ-54175446 is a high affinity (and potency) P2X7 antagonist that displays pharmacology at recombinant human, rat, mouse, macaque, and dog P2X7. In native systems, this compound displayed P2X7 pharmacology as well: it blocked P2X7-dependent IL-1 $\beta$ release in human blood and displayed binding to rat, dog, and human brain sections. Target engagement in rat brain was demonstrated for JNJ-54175446 utilizing ex vivo autoradiography. The molecule showed dose-dependent brain P2X7 occupancy with an $\mathrm{ED}_{50}$ of $0.46 \mathrm{mg} / \mathrm{kg}$, which corresponded to plasma $\mathrm{EC}_{50}$ of $105 \mathrm{ng} / \mathrm{ml}$. This compound efficiently crossed into the brain compartment with a brain/plasma ratio of approximately 1.1 in rat. JNJ-54175446 demonstrated robust and sustained P2X7 brain occupancy in the rat following a $10 \mathrm{mg} / \mathrm{kg}$ oral dose (>80\% occupancy for $24 \mathrm{~h}$ ). Consistent with rat brain target engagement, the compound did attenuate brain IL-1 $\beta$ release,

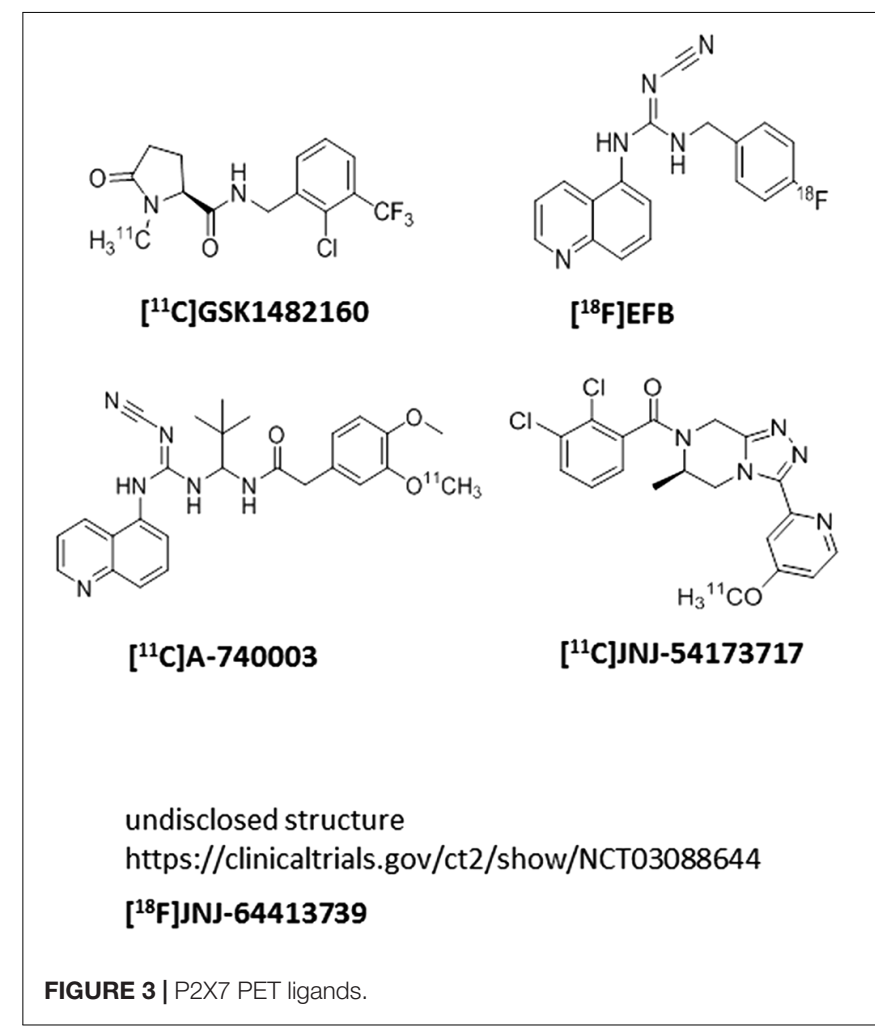

as measured by microdialysis. When the molecule was dosed in a higher species (i.e., dog), JNJ-54175446 also bound to dog brain P2X7, and blocked dog blood IL-1 $\beta$ release, providing a model of both central and peripheral target engagement in one 
species. This data highlights the fact that blood IL-1 $\beta$ can be used as a biomarker, and may be a surrogate for central target engagement in the absence of a PET ligand. As has been described later on, there are several P2X7 PET ligands that should enable human target engagement (i.e., human brain P2X7) studies. Given the excellent target engagement data in rats and dogs, JNJ54175446 was profiled further to enrich clinical candidacy data package including toxicity and cardiovascular safety studies. JNJ55308942, has been chosen as the second P2X7 antagonist from Janssen to enter clinical trials, as a back-up to JNJ-54175446. While maintaining the superior P2X7 pharmacology of the lead molecule, JNJ-55308942 provides significant improvement in solubility and protein binding properties (i.e., increased free fraction). JNJ-55308942 showed excellent P2X7 receptor occupancy in the hippocampus of rats, demonstrating a low $\mathrm{ED}_{50}$ of $0.07 \mathrm{mg} / \mathrm{kg}$. The compound also demonstrated good tolerability margins in preclinical species, as well as an acceptable cardiovascular safety profile in vivo.

In addition to Janssen's efforts, several other companies (Affectis, Axxam, Actelion, Lundbeck) have published patents on brain-penetrant P2X7 scaffolds (Park and Kim, 2017). Both Lundbeck and Axxam Pharmaceuticals published patents disclosing CNS-penetrant P2X7 antagonists, with Axxam entering into a collaborative agreement with Alzheimer's drug discovery foundation to understand the role of centrally penetrant P2X7 antagonists in Alzheimer's. Lastly, AFC-5128 is a brain-penetrant P2X7 antagonist from Affectis Pharmaceuticals that is being pushed for neuropathic pain and multiple sclerosis indications (company website).

\section{P2X7 PET LIGANDS}

Several P2X7 PET ligands have been described in the literature recently (Figure 3); there are two clinical utilities of P2X7 PET ligands that cross the blood-brain barrier: (a) the PET ligands can be used as a probe to measure central target occupancy of the clinical compound being developed for a CNS indication; (b) since $\mathrm{P} 2 \mathrm{X} 7$ activation is related to microglial activation, P2X7 PET ligands can potentially be used as central biomarkers of assessing microglial activation in diseases accompanying neuroinflammation such as mood disorders, schizophrenia, epilepsy, multiple sclerosis, and others. Our team has disclosed a $\left[{ }^{11} \mathrm{C}\right]$-labeled P2X7 PET ligand (JNJ-54173717), where it was shown that P2X7 overexpression can be detected under basal and overexpressed conditions and the PET signal was blocked by competition with cold P2X7 ligands in a dose-dependent manner in rats (Ory et al., 2016). A second P2X7 PET ligand,

\section{REFERENCES}

Abdi, M. H., Beswick, P. J., Billinton, A., Chambers, L. J., Charlton, A., Collins, S. D., et al. (2010). Discovery and structure-activity relationships of a series of pyroglutamic acid amide antagonists of the $\mathrm{P}_{2} \mathrm{X}_{7}$ receptor. Bioorg. Med. Chem. Lett. 20, 5080-5084. doi: 10.1016/j.bmcl.2010.07.033

Ali, Z., Laurijssens, B., Ostenfeld, T., McHugh, S., Stylianou, A., Scott-Stevens, P., et al. (2013). Pharmacokinetic and pharmacodynamic profiling of a P2X7 with $\left[{ }^{18} \mathrm{~F}\right]$ label (JNJ-64413739), has been recently described at the American College of Neuropsychopharmacology conference (December, 2017) where it was elegantly demonstrated that JNJ-54175446 (i.e., the clinical compound shown in Figure 1) was able to displace $\left[{ }^{18} \mathrm{~F}\right] \mathrm{JNJ}-64413739$ PET signal in healthy human subjects in a dose-dependent manner (NCT03088644). Similarly, the $\left[{ }^{11} \mathrm{C}\right] \mathrm{GSK} 1482160$ PET signal in the brain of LPS challenged rats was also blocked by a cold P2X7 antagonist, demonstrating specificity of the PET signal to P2X7 (Territo et al., 2017). In addition to $\left[{ }^{18} \mathrm{~F}\right] J N J-64413739,\left[{ }^{11} \mathrm{C}\right] J N J-54173717$, and [11C]GSK1482160, two other groups have disclosed P2X7 PET ligands $\left(\left[{ }^{11} \mathrm{C}\right] \mathrm{A}-7400003\right.$ and $\left.\left[{ }^{18} \mathrm{~F}\right]-\mathrm{EFB}\right)$, albeit with no data to support P2X7 specificity of the brain signal (Janssen et al., 2014; Fantoni et al., 2017). The field has made significant progress in discovery of brain-penetrant P2X7 antagonists in recent years. Molecules such as JNJ-54175446 will now need to be tested in clinical settings to find efficacy signals in psychiatric disorders; persistent and prudent drug developmental paradigms, out-ofbox thinking, challenging the status-quo, may result in a P2X7 therapeutic that will benefit patients suffering from life-changing CNS disorders.

\section{CONCLUSION AND PERSPECTIVES}

The unmet medical need in neuropsychiatry is staggering; it is clear from existing clinical data that "one pill fits all" strategy has not worked. Patients suffering from depression, bipolar disorder, and schizophrenia may have neuroinflammatory causality of the disease, and not every patient carries similar inflammatory disease burden. While there are patients that will benefit from existing pharmacotherapy, a huge sub-population of patients will respond better to therapies that address the underlying cause of the disease and the hope is CNS P2X7 antagonists in clinical trials will advance into proof of concept studies either as monotherapy or as adjunctives for neuropsychiatric disorders.

\section{AUTHOR CONTRIBUTIONS}

$\mathrm{AB}$ conceived the topic for the mini-review and wrote the draft of the manuscript.

\section{ACKNOWLEDGMENTS}

The author acknowledges the contribution of Devin Swanson and Michael Letavic for providing feedback on the manuscript. receptor allosteric modulator GSK1482160 in healthy human subjects. Br. J. Clin. Pharmacol. 75, 197-207. doi: 10.1111/j.1365-2125.2012.04320.x

Backlund, L., Lavebratt, C., Frisen, L., Nikamo, P., Hukic Sudic, D., TraskmanBendz, L., et al. (2012). P2RX7: expression responds to sleep deprivation and associates with rapid cycling in bipolar disorder type 1. PLOS ONE 7:e43057. doi: 10.1371/journal.pone.0043057

Backlund, L., Nikamo, P., Hukic, D. S., Ek, I. R., Traskman-Bendz, L., Landen, M., et al. (2011). Cognitive manic symptoms associated with the P2RX7 gene in 
bipolar disorder. Bipolar Disord. 13, 500-508. doi: 10.1111/j.1399-5618.2011. 00952.x

Barden, N., Harvey, M., Gagne, B., Shink, E., Tremblay, M., Raymond, C., et al. (2006). Analysis of single nucleotide polymorphisms in genes in the chromosome 12Q24.31 region points to P2RX7 as a susceptibility gene to bipolar affective disorder. Am. J. Med. Genet B Neuropsychiatr. Genet. 141B, 374-382.

Bartlett, R., Stokes, L., and Sluyter, R. (2014). The P2X7 receptor channel: recent developments and the use of P2X7 antagonists in models of disease. Pharmacol. Rev. 66, 638-675. doi: 10.1124/pr.113.008003

Basso, A. M., Bratcher, N. A., Harris, R. R., Jarvis, M. F., Decker, M. W., and Rueter, L. E. (2009). Behavioral profile of P2X7 receptor knockout mice in animal models of depression and anxiety: relevance for neuropsychiatric disorders. Behav. Brain Res. 198, 83-90. doi: 10.1016/j.bbr.2008.10.018

Beswick, P. J., Billinton, A., Chambers, L. J., Dean, D. K., Fonfria, E., Gleave, R. J., et al. (2010). Structure-activity relationships and in vivo activity of (1H-pyrazol4-yl) acetamide antagonists of the P2X(7) receptor. Bioorg. Med. Chem. Lett. 20, 4653-4656. doi: 10.1016/j.bmcl.2010.05.107

Bhattacharya, A., and Biber, K. (2016). The microglial ATP-gated ion channel P2X7 as a CNS drug target. Glia 64, 1772-1787. doi: 10.1002/glia.23001

Bhattacharya, A., Derecki, N. C., Lovenberg, T. W., and Drevets, W. C. (2016). Role of neuro-immunological factors in the pathophysiology of mood disorders. Psychopharmacology 233, 1623-1636. doi: 10.1007/s00213-016-4214-0

Bhattacharya, A., and Drevets, W. C. (2017). Role of neuro-immunological factors in the pathophysiology of mood disorders: implications for novel therapeutics for treatment resistant depression. Curr. Top. Behav. Neurosci. 31, 339-356. doi: 10.1007/7854_2016_43

Bhattacharya, A., Wang, Q., Ao, H., Shoblock, J. R., Lord, B., Aluisio, L., et al. (2013). Pharmacological characterization of a novel centrally permeable P2X7 receptor antagonist: JNJ-47965567. Br. J. Pharmacol. 170, 624-640. doi: 10. 1111/bph.12314

Boucher, A. A., Arnold, J. C., Hunt, G. E., Spiro, A., Spencer, J., Brown, C., et al. (2011). Resilience and reduced c-Fos expression in P2X7 receptor knockout mice exposed to repeated forced swim test. Neuroscience 189, 170-177. doi: 10.1016/j.neuroscience.2011.05.049

Calcia, M. A., Bonsall, D. R., Bloomfield, P. S., Selvaraj, S., Barichello, T., and Howes, O. D. (2016). Stress and neuroinflammation: a systematic review of the effects of stress on microglia and the implications for mental illness. Psychopharmacology 233, 1637-1650. doi: 10.1007/s00213-016-4218-9

Chen, X., Pierce, B., Naing, W., Grapperhaus, M. L., and Phillion, D. P. (2010). Discovery of 2-chloro-N-((4,4-difluoro-1-hydroxycyclohexyl)methyl)5-(5-fluoropyrimidin-2-yl)b enzamide as a potent and CNS penetrable P2X7 receptor antagonist. Bioorg. Med. Chem. Lett. 20, 3107-3111. doi: 10.1016/j. bmcl.2010.03.094

Chrovian, C. C., Rech, J. C., Bhattacharya, A., and Letavic, M. A. (2014). P2X7 antagonists as potential therapeutic agents for the treatment of CNS disorders. Progr. Med. Chem. 53, 65-100. doi: 10.1016/B978-0-444-63380-4.00002-0

Chrovian, C. C., Soyode-Johnson, A., Peterson, A. A., Gelin, C. F., Deng, X., Dvorak, C. A., et al. (2017). A dipolar cycloaddition reaction to access 6-methyl4,5,6,7-tetrahydro- $1 \mathrm{H}$-[1,2,3]triazolo[4,5-c]pyridines enables the discovery synthesis and preclinical profiling of a P2X7 antagonist clinical candidate. J. Med. Chem. 61, 207-223. doi: 10.1021/acs.jmedchem.7b01279

Corwin, E. J., Johnston, N., and Pugh, L. (2008). Symptoms of postpartum depression associated with elevated levels of interleukin-1 beta during the first month postpartum. Biol. Res. Nurs. 10, 128-133. doi: 10.1177/ 1099800408323220

Csolle, C., Ando, R. D., Kittel, A., Goloncser, F., Baranyi, M., Soproni, K., et al. (2013a). The absence of P2X7 receptors (P2rx7) on non-haematopoietic cells leads to selective alteration in mood-related behaviour with dysregulated gene expression and stress reactivity in mice. Int. J. Neuropsychopharmacol. 16, 213-233. doi: 10.1017/S1461145711001933

Csolle, C., Baranyi, M., Zsilla, G., Kittel, A., Goloncser, F., Illes, P., et al. (2013b). Neurochemical changes in the mouse hippocampus underlying the antidepressant effect of genetic deletion of $\mathrm{P} 2 \mathrm{X} 7$ receptors. PLOS ONE 8:e66547. doi: 10.1371/journal.pone.0066547

Czamara, D., Muller-Myhsok, B., and Lucae, S. (2017). The P2RX7 polymorphism rs2230912 is associated with depression: a meta-analysis. Progr. Neuro Psychopharmacol. Biol. Psychiatry doi: 10.1016/j.pnpbp.2017.11.003 [Epub ahead of print].
De Marchi, E., Orioli, E., Dal Ben, D., and Adinolfi, E. (2016). P2X7 receptor as a therapeutic target. Adv. Protein Chem. Struct. Biol. 104, 39-79. doi: 10.1016/bs. apcsb.2015.11.004

Diniz, B. S., Teixeira, A. L., Talib, L., Gattaz, W. F., and Forlenza, O. V. (2010). Interleukin-1 $\beta$ serum levels is increased in antidepressant-free elderly depressed patients. Am. J. Geriatr. Psychiatry 18, 172-176. doi: 10.1097/JGP. 0b013e3181c2947f

Duplantier, A. J., Dombroski, M. A., Subramanyam, C., Beaulieu, A. M., Chang, S. P., Gabel, C. A., et al. (2011). Optimization of the physicochemical and pharmacokinetic attributes in a 6-azauracil series of $\mathrm{P}_{2} \mathrm{X}_{7}$ receptor antagonists leading to the discovery of the clinical candidate CE-224,535. Bioorg. Med. Chem. Lett. 21, 3708-3711. doi: 10.1016/j.bmcl.2011. 04.077

Eser, A., Colombel, J.-F., Rutgeerts, P., Vermeire, S., Vogelsang, H., Braddock, M., et al. (2015). Safety and Efficacy of an oral inhibitor of the purinergic receptor $\mathrm{P}_{2} \mathrm{X}_{7}$ in adult patients with moderately to severely active crohn's disease: a randomized placebo-controlled, double-blind, phase IIa study. Inflamm. Bowel Dis. 21, 2247-2253. doi: 10.1097/MIB.0000000000000514

Fantoni, E. R., Dal Ben, D., Falzoni, S., Di Virgilio, F., Lovestone, S., and Gee, A. (2017). Design, synthesis and evaluation in an LPS rodent model of neuroinflammation of a novel 18F-labelled PET tracer targeting P2X7. EJNMMI Res. 7:31. doi: 10.1186/s13550-017-0275-2

Feng, W. P., Zhang, B., Li, W., and Liu, J. (2014). Lack of association of P2RX7 gene rs2230912 polymorphism with mood disorders: a meta-analysis. PLOS ONE 9:e88575. doi: 10.1371/journal.pone.0088575

Giuliani, A. L., Sarti, A. C., Falzoni, S., and Di Virgilio, F. (2017). The P2X7 receptor-interleukin-1 liaison. Front. Pharmacol. 8:123. doi: 10.3389/fphar. 2017.00123

Gubert, C., Fries, G. R., Pfaffenseller, B., Ferrari, P., Coutinho-Silva, R., Morrone, F. B., et al. (2014). Role of P2X7 receptor in an animal model of mania induced by D-amphetamine. Mol. Neurobiol. 53, 611-620. doi: 10.1007/s12035-0149031-z

Halmai, Z., Dome, P., Vereczkei, A., Abdul-Rahman, O., Szekely, A., Gonda, X., et al. (2013). Associations between depression severity and purinergic receptor P2RX7 gene polymorphisms. J. Affect. Disord. 150, 104-109. doi: 10.1016/j.jad. 2013.02.033

He, Y., Taylor, N., Fourgeaud, L., and Bhattacharya, A. (2017). The role of microglial P2X7: modulation of cell death and cytokine release. J. Neuroinflammat. 14:135. doi: 10.1186/s12974-017-0904-8

Hejjas, K., Szekely, A., Domotor, E., Halmai, Z., Balogh, G., Schilling, B., et al. (2009). Association between depression and the Gln460Arg polymorphism of P2RX7 gene: a dimensional approach. Am. J. Med. Genet. B Neuropsychiatr. Genet. 150B, 295-299. doi: 10.1002/ajmg.b.30799

Illes, P., Khan, T. M., and Rubini, P. (2017). Neuronal P2X7 receptors revisited: do they really exist? J. Neurosci. 37, 7049-7062. doi: 10.1523/JNEUROSCI.310316.2017

Iwata, M., Ota, K. T., Li, X.-Y., Sakaue, F., Li, N., Dutheil, S., et al. (2016). Psychological stress activates the inflammasome via release of ATP and stimulation of the P2X7 receptor. Biol. Psychiatry 80, 12-22. doi: 10.1016/j. biopsych.2015.11.026

Jansen, R., Penninx, B. W., Madar, V., Xia, K., Milaneschi, Y., Hottenga, J. J., et al. (2016). Gene expression in major depressive disorder. Mol. Psychiatry 21, 339-47. doi: 10.1038/mp.2015.57

Janssen, B., Vugts, D. J., Funke, U., Spaans, A., Schuit, R. C., Kooijman, E., et al. (2014). Synthesis and initial preclinical evaluation of the P2X7 receptor antagonist $[(1)(1) \mathrm{C}] \mathrm{A}-740003$ as a novel tracer of neuroinflammation. J. Labelled Comp. Radiopharm. 57, 509-516. doi: 10.1002/jlcr.3206

Jones, K. A., and Thomsen, C. (2013). The role of the innate immune system in psychiatric disorders. Mol. Cell. Neurosci. 53, 52-62. doi: 10.1016/j.mcn.2012. 10.002

Karasawa, A., and Kawate, T. (2016). Structural basis for subtype-specific inhibition of the P2X7 receptor. eLife 5:e22153. doi: 10.7554/eLife.22153

Karasawa, A., Michalski, K., Mikhelzon, P., and Kawate, T. (2017). The P2X7 receptor forms a dye-permeable pore independent of its intracellular domain but dependent on membrane lipid composition. eLife 6:e31186. doi: 10.7554/ eLife. 31186

Keystone, E. C., Wang, M. M., Layton, M., Hollis, S., McInnes, I. B., and Team, D. C. S. (2012). Clinical evaluation of the efficacy of the P2X7 purinergic receptor antagonist AZD9056 on the signs and symptoms of rheumatoid 
arthritis in patients with active disease despite treatment with methotrexate or sulphasalazine. Ann. Rheumat. Dis. 71, 1630-1635.

Koo, J. W., and Duman, R. S. (2009). Evidence for IL-1 receptor blockade as a therapeutic strategy for the treatment of depression. Curr. Opin. Investig. Drugs 10, 664-671.

Kovanyi, B., Csolle, C., Calovi, S., Hanuska, A., Kato, E., Koles, L., et al. (2016). The role of P2X7 receptors in a rodent PCP-induced schizophrenia model. Sci. Rep. 6:36680. doi: 10.1038/srep36680

Laskaris, L. E., Di Biase, M. A., Everall, I., Chana, G., Christopoulos, A., Skafidas, E., et al. (2016). Microglial activation and progressive brain changes in schizophrenia. Br. J. Pharmacol. 173, 666-680. doi: 10.1111/bph. 13364

Leday, G. G. R., Vertes, P. E., Richardson, S., Greene, J. R., Regan, T., Khan, S., et al. (2018). Replicable and coupled changes in innate and adaptive immune gene expression in two case-control studies of blood microarrays in major depressive disorder. Biol. Psychiatry 83, 70-80. doi: 10.1016/j.biopsych.2017.01.021

Leighton, S. P., Nerurkar, L., Krishnadas, R., Johnman, C., Graham, G. J., and Cavanagh, J. (2017). Chemokines in depression in health and in inflammatory illness: a systematic review and meta-analysis. Mol. Psychiatry 23, 48-58. doi: 10.1038/mp.2017.205

Letavic, M. A., Lord, B., Bischoff, F., Hawryluk, N. A., Pieters, S., Rech, J. C., et al. (2013). Synthesis and pharmacological characterization of two novel, brain penetrating P2X7 antagonists. ACS Med. Chem. Lett. 4, 419-422. doi: $10.1021 / \mathrm{ml} 400040 \mathrm{v}$

Letavic, M. A., Savall, B. M., Allison, B. D., Aluisio, L., Andres, J. I., De Angelis, M., et al. (2017). 4-Methyl-6,7-dihydro-4H-triazolo[4,5-c]pyridinebased P2X7 receptor antagonists: optimization of pharmacokinetic properties leading to the identification of a clinical candidate. J. Med. Chem. 60, 4559-4572. doi: 10.1021/acs.jmedchem.7b00408

Lord, B., Aluisio, L., Shoblock, J. R., Neff, R. A., Varlinskaya, E. I., Ceusters, M., et al. (2014). Pharmacology of a novel central nervous system-penetrant P2X7 antagonist JNJ-42253432. J. Pharmacol. Exp. Ther. 351, 628-641. doi: 10.1124/ jpet.114.218487

Lord, B., Ameriks, M. K., Wang, Q., Fourgeaud, L., Vliegen, M., Verluyten, W., et al. (2015). A novel radioligand for the ATP-gated ion channel P2X7: [3H] JNJ-54232334. Eur. J. Pharmacol. 765, 551-559. doi: 10.1016/j.ejphar.2015. 09.026

Louveau, A., Smirnov, I., Keyes, T. J., Eccles, J. D., Rouhani, S. J., Peske, J. D., et al. (2015). Structural and functional features of central nervous system lymphatic vessels. Nature 523, 337-341. doi: 10.1038/nature14432

Lovenberg, T., Aluisio, L., Ceusters, M., Letavic, M., and Bhattacharya, A. (2015). "Characterization of $\mathrm{P} 2 \mathrm{X} 7$ antagonists in the rodent brain: promise for a novel mechanism of action for mood disorder?," in Proceedings of the CINP Thematic Meeting on Stress, Inflammation and Depression: Focus on Novel Antidepressant Targets, Dublin.

Lucae, S., Salyakina, D., Barden, N., Harvey, M., Gagne, B., Labbe, M., et al. (2006). P2RX7, a gene coding for a purinergic ligand-gated ion channel, is associated with major depressive disorder. Hum. Mol. Genet. 15, 2438-2445. doi: $10.1093 / \mathrm{hmg} / \mathrm{ddl} 166$

Miller, A. H., Haroon, E., and Felger, J. C. (2017). Therapeutic implications of brain-immune interactions: treatment in translation. Neuropsychopharmacology 42, 334-359. doi: 10.1038/npp.2016.167

Mondelli, V., Vernon, A. C., Turkheimer, F., Dazzan, P., and Pariante, C. M. (2017). Brain microglia in psychiatric disorders. Lancet Psychiatry 4, 563-572. doi: 10.1016/S2215-0366(17)30101-3

Monif, M., Burnstock, G., and Williams, D. A. (2010). Microglia: proliferation and activation driven by the P2X7 receptor. Int. J. Biochem. Cell Biol. 42, 1753-1756. doi: 10.1016/j.biocel.2010.06.021

Nelson, D. W., Gregg, R. J., Kort, M. E., Perez-Medrano, A., Voight, E. A., Wang, Y., et al. (2006). Structure-activity relationship studies on a series of novel, substituted 1-benzyl-5-phenyltetrazole P2X7 antagonists. J. Med. Chem. 49, 3659-3666. doi: 10.1021/jm051202e

Ory, D., Celen, S., Gijsbers, R., Van Den Haute, C., Postnov, A., Koole, M., et al. (2016). Preclinical Evaluation of a P2X7 receptor-selective radiotracer: PET studies in a rat model with local overexpression of the human P2X7 receptor and in nonhuman primates. J. Nucl. Med. 57, 1436-1441. doi: 10.2967/jnumed. 115.169995

Otrokocsi, L., Kittel, A., and Sperlagh, B. (2017). P2X7 receptors drive spine synapse plasticity in the learned helplessness model of depression. Int. J. Neuropsychopharmacol. 20, 813-822. doi: 10.1093/ijnp/pyx046
Park, J. H., and Kim, Y. C. (2017). P2X7 receptor antagonists: a patent review (2010-2015). Exp. Opin. Therap. Patents 27, 257-267. doi: 10.1080/13543776. 2017.1246538

Pippel, A., Stolz, M., Woltersdorf, R., Kless, A., Schmalzing, G., and Markwardt, F. (2017). Localization of the gate and selectivity filter of the full-length P2X7 receptor. Proc. Natl. Acad. Sci. U.S.A. 114, E2156-E2165. doi: 10.1073/pnas. 1610414114

Savall, B. M., Wu, D., De Angelis, M., Carruthers, N. I., Ao, H., Wang, Q., et al. (2015). Synthesis, SAR, and pharmacological characterization of brain penetrant P2X7 receptor antagonists. ACS Med. Chem. Lett. 6, 671-676. doi: 10.1021/acsmedchemlett.5b00089

Söderlund, J., Olsson, S. K., Samuelsson, M., Walther-Jallow, L., Johansson, C., Erhardt, S., et al. (2011). Elevation of cerebrospinal fluid interleukin-1ß in bipolar disorder. J. Psychiatry Neurosci. 36, 114-118. doi: 10.1503/jpn.100080

Soronen, P., Mantere, O., Melartin, T., Suominen, K., Vuorilehto, M., Rytsala, H., et al. (2011). P2RX7 gene is associated consistently with mood disorders and predicts clinical outcome in three clinical cohorts. Am. J. Med. Genet. B Neuropsychiat. Genet. 156B, 435-447. doi: 10.1002/ajmg.b.31179

Sperlagh, B., and Illes, P. (2014). P2X7 receptor: an emerging target in central nervous system diseases. Trends Pharmacol. Sci. 35, 537-547. doi: 10.1016/j.tips. 2014.08.002

Stock, T. C., Bloom, B. J., Wei, N., Ishaq, S., Park, W., Wang, X., et al. (2012). Efficacy and safety of CE-224,535, an antagonist of $\mathrm{P} 2 \mathrm{X} 7$ receptor, in treatment of patients with rheumatoid arthritis inadequately controlled by methotrexate. J. Rheumatol. 39, 720-727. doi: 10.3899/jrheum.110874

Stokes, L., Fuller, S. J., Sluyter, R., Skarratt, K. K., Gu, B. J., and Wiley, J. S. (2010). Two haplotypes of the P2X(7) receptor containing the Ala-348 to Thr polymorphism exhibit a gain-of-function effect and enhanced interleukin-1beta secretion. FASEB J. 24, 2916-2927. doi: 10.1096/fj.09-150862

Stokes, L., Spencer, S. J., and Jenkins, T. A. (2015). Understanding the role of P2X7 in affective disorders-are glial cells the major players? Front. Cell. Neurosci. 9:258. doi: $10.3389 /$ fncel.2015.00258

Swanson, D. M., Savall, B. M., Coe, K. J., Schoetens, F., Koudriakova, T., Skaptason, J., et al. (2016). Identification of (R)-(2-Chloro-3-(trifluoromethyl) phenyl)(1-(5-fluoropyridin-2-yl)-4-methyl-6,7-di hydro-1H-imidazo[4,5c]pyridin-5(4H)-yl)methanone (JNJ 54166060), a Small Molecule Antagonist of the P2X7 receptor. J. Med. Chem. 59, 8535-8548. doi: 10.1021/acs.jmedchem. $6 \mathrm{~b} 00989$

Tan, S., Wang, Y., Chen, K., Long, Z., and Zou, J. (2017). Ketamine alleviates depressive-like behaviors via down-regulating inflammatory cytokines induced by chronic restraint stress in mice. Biol. Pharmaceut. Bull. 40, 1260-1267. doi: 10.1248/bpb.b17-00131

Territo, P. R., Meyer, J. A., Peters, J. S., Riley, A. A., McCarthy, B. P., Gao, M., et al. (2017). Characterization of 11C-GSK1482160 for targeting the P2X7 receptor as a biomarker for neuroinflammation. J. Nuclear Med. 58, 458-465. doi: 10.2967/jnumed.116.181354

Wetsman, N. (2017). Inflammatory illness: why the next wave of antidepressants may target the immune system. Nat. Med. 23, 1009-1011. doi: 10.1038/nm09171009

Wilkinson, S. M., Gunosewoyo, H., Barron, M. L., Boucher, A., McDonnell, M., Turner, P., et al. (2014). The first CNS-active carborane: a novel P2X7 receptor antagonist with antidepressant activity. ACS Chem. Neurosci. 5, 335-339. doi: $10.1021 / \mathrm{cn} 500054 \mathrm{n}$

Wohleb, E. S., Franklin, T., Iwata, M., and Duman, R. S. (2016). Integrating neuroimmune systems in the neurobiology of depression. Nat. Rev. Neurosci. 17, 497-511. doi: 10.1038/nrn.2016.69

Yue, N., Huang, H., Zhu, X., Han, Q., Wang, Y., Li, B., et al. (2017). Activation of P2X7 receptor and NLRP3 inflammasome assembly in hippocampal glial cells mediates chronic stress-induced depressive-like behaviors. J. Neuroinflammation 14:102. doi: 10.1186/s12974-017-0865-y

Conflict of Interest Statement: The author is a full-time employee of Johnson \& Johnson.

Copyright (@) 2018 Bhattacharya. This is an open-access article distributed under the terms of the Creative Commons Attribution License (CC BY). The use, distribution or reproduction in other forums is permitted, provided the original author(s) and the copyright owner are credited and that the original publication in this journal is cited, in accordance with accepted academic practice. No use, distribution or reproduction is permitted which does not comply with these terms. 